\title{
Genetic evidence for migration of males between schools of the long-finned pilot whale Globicephala melas
}

\author{
Liselotte Wesley Andersen $^{1, *}$, Hans Redlef Siegismund ${ }^{2}$ \\ 'Institute of Natural Science, University of the Faroe Islands, Noatún, 100 Tórshavn, Faroe Islands \\ ${ }^{2}$ Arboretum, Royal Veterinary and Agricultural University, Kirkegårdsvej 3A, DK-2970 Hørsholm, Denmark
}

\begin{abstract}
The genetic variation at 3 polymorphic allozyme loci was investigated in a population sample comprising approximately 650 individuals of the long-finned pilot whale Globicephala melas caught in the Faroe Islands. The sample consisted of pregnant females (carrying foetuses), nonpregnant females and males. The genetic variation was analyzed with a selection component analysis. At 2 of the loci the hypothesis of no male reproductive selection was rejected. It was concluded that the fathers of the foetuses differed genotypically from the males found in the schools, indicating that males migrate between schools to mate
\end{abstract}

KEY WORDS: Selection component analysis - Globicephala melas - Migration - Allozyme data

\section{INTRODUCTION}

Allozyme studies of the genetic variation and population structure of the long-finned pilot whale Globicephala melas (Andersen 1988, 1993) have revealed significant differences in allele frequencies among a number of the 31 schools analyzed. This heterogeneity was not influenced by the age structure in the total sample nor could it be explained by a geographically segregated population structure. The question is, how can we explain this observation, and how do we interpret the population structure of the long-finned pilot whale? The following results from earlier studies provide some possible, but inconclusive answers: (1) allele frequency differences were most frequent among females from different schools, implying that females within schools are more closely related to each other than to females in different schools; (2) significant deviations from Hardy-Weinberg proportions reflected by males in several schools could imply a migration of males between schools, although the effect of natural

\footnotetext{
- Present address: Dept of Genetics and Ecology, University of Århus, Ny Munkegade, DK-8000 Århus C, Denmark
}

selection cannot be excluded; (3) the detected linkage disequilibrium could also be maintained by migration of mature males between schools.

The school size for 10 schools of the long-finned pilot whale caught at the Faroe Islands between 1976 and 1986 ranged from 24 to 316 individuals. It is known from observations that the long-finned pilot whale forms herds containing up to 2000 individuals (Brown 1961). This suggests that long-finned pilot whale schools fuse, but it is not known whether the herds reform into the original schools or whether new schools are produced. Furthermore, in a DNA-fingerprinting study Amos et al. (1991) have found that for a large fraction of the foetuses, the accompanying males could not be the fathers. This led to the suggestion that the observed heterogeneity arises from combinations of school fusions and fissions, migration of mature males between the schools, and a strong maternal family structure within the schools consisting of several female lineages.

In the present study we apply the selection component analysis of Christiansen \& Frydenberg (1973) using allozyme data from mother-offspring combinations from earlier studies to test the hypothesis of a sexspecific migration between the schools. 


\section{MATERIAL AND METHODS}

Material. Globicephala melas is a relatively small whale; females and males may reach lengths of 5 and $6 \mathrm{~m}$, respectively. Females become sexually mature at the age of $6 \mathrm{yr}$, whereas males reach maturity at $12 \mathrm{yr}$ (Desportes 1985). The current estimate of the population size around the Faroe Islands is 778000 (CV = 0.295) (Buckland et al. 1993).

In connection with an international research program on the biology of the long-finned pilot whales off the Faroe Islands, which ran from 1986 to 1988 , tissue samples were collected from 31 schools and used in allozyme studies (Andersen 1988, in press). The nature of the Faroese drive fishery for pilot whales is such that whole schools are caught in an opportunistic catch, which means that the sample is unbiased. ('Schools' is the ordinary term used for pilot whales and refers to the group of individuals caught in the drive fishery.)

Methods. Three polymorphic allozyme loci were used: Est-1, esterase, E.C. 3.1.1.1; Mpi, mannose phosphate isomerase, E.C. 5.3.1.8; and Sod-1, superoxide dismutase, E.C. 1.15.1.1 (Andersen 1988).

Analysis of the population structure revealed that the population of long-finned pilot whale schools off the Faroe Islands was heterogeneous. In the present study we have therefore chosen to restrict the total sample of 31 schools to only the largest homogeneous group of schools containing foetuses. The largest homogeneous group of schools was found by means of a $G_{H}$-test of independence in an $\mathrm{R} \times \mathrm{C}$ contingency table performed on total number of alleles in each school (Sokal \& Rohlf 1981). The largest number of schools providing sufficient material for examination of each of the 3 loci was then chosen to represent the sample. The total sample for the loci Mpi and Sod-1 consisted of the following 19 schools: 860712, 860911, $860915,860925,861025,861101,861111,861115$. $861128,861223,870122,870207,870323,870410$, $870516,870722,870724,870802,870829$.

The total sample for the Est-1 locus included 13 of these schools, where 861025 . $870122,870207,870323,870410,870516$ were excluded due to lack of liver samples (Andersen 1993).

The allozyme data from these schools consist of a population sample that includes mother-offspring combinations, non-pregnant females and males. The format of the data set is well suited for analysis with the selection component method of Christiansen \& Frydenberg (1973). This analysis formulates a sequence of increasingly restrictive hypotheses about the data, and tests for the action of several components of natural selection: gametic selection, sexual selection and zygotic selection. In addition, it tests for random mating. We have chosen to use the terms 'mothers' (or 'pregnant females') and 'non-pregnant females' instead of 'fertile' and 'sterile' females, in accordance with the use in later applications of selection component analysis (see e.g. Christiansen et al. 1973). The use of 'pregnant' and 'nonpregnant' emphasizes that females in 1 of these 2 groups of iteroparous organisms may have been in the other group at other stages in their life history. Some of the hypotheses of selection component analysis may seem crude from a biological point of view, but they are probably the best that can be tested statistically with a population sample such as the present one. The titles of the hypotheses (see 'Results') are as in Christiansen \& Frydenberg (1973). In the original analysis, the hypotheses were tested by comparison of expected and observed distributions with $\chi^{2}$ goodness-of-fit tests. We have chosen to use likelihood-ratio tests, a procedure that was adopted in later extensions of the selection component analysis (Østergaard \& Christiansen 1981, Siegismund \& Christiansen 1985). The differences between these test statistics and the goodness-of-fit test statistics were always small. Estimates of the genotypic distributions of males that fathered offspring were established using the gene counting procedure outlined by Christiansen et al. (1977). Williams et al. (1990) have presented an alternative, but we have chosen to adhere to the original procedures.

\section{RESULTS}

The genotypic distributions at the 3 studied loci, Est-1, Mpi, and Sod-1, are given in Tables 1 to 3 for the population sample. All 3 loci are polymorphic with 2 common alleles, denoted $A_{1}$ and $A_{2}$. The sample size

Table 1 Globicephala melas. Est-1 locus: observed genotypic distributions, and expected (in italic type) distributions under Hypothesis 6 . The expected numbers of offspring are conditional on the observed numbers of mothers

\begin{tabular}{|c|c|c|c|c|c|c|}
\hline \multirow[t]{2}{*}{ Mother } & \multicolumn{3}{|c|}{ Offspring } & \multirow{2}{*}{$\begin{array}{l}\text { Sum of } \\
\text { mothers }\end{array}$} & \multirow{2}{*}{$\begin{array}{l}\text { Non-breeding } \\
\text { females }\end{array}$} & \multirow[t]{2}{*}{ Males } \\
\hline & $A_{1} A_{1}$ & $A_{1} A_{2}$ & $A_{2} A_{2}$ & & & \\
\hline$A_{1} A_{1}$ & $\begin{array}{l}19 \\
19.6\end{array}$ & $\begin{array}{l}8 \\
7.4\end{array}$ & & $\begin{array}{l}27 \\
24.2\end{array}$ & $\begin{array}{l}80 \\
75.3\end{array}$ & $\begin{array}{l}28 \\
36.9\end{array}$ \\
\hline$A_{1} A_{2}$ & $\begin{array}{l}8 \\
6.9\end{array}$ & $\begin{array}{l}10 \\
9.5\end{array}$ & $\begin{array}{l}1 \\
2.6\end{array}$ & $\begin{array}{l}19 \\
18.3\end{array}$ & $\begin{array}{l}53 \\
56.9\end{array}$ & $\begin{array}{l}33 \\
27.9\end{array}$ \\
\hline$A_{2} A_{2}$ & & 0 & 0 & $\begin{array}{l}0 \\
3.5\end{array}$ & $\begin{array}{l}10 \\
10.8\end{array}$ & $\begin{array}{l}9 \\
5.3\end{array}$ \\
\hline Sum & 27 & 18 & 1 & 46 & 143 & 70 \\
\hline
\end{tabular}


Table 2. Globicephala melas. Mpi locus: observed genotypic distributions, and expected distributions (in italic type) of offspring and males under Hypothesis 3 and of females under Hypothesis 4 . The expected numbers of offspring are conditional on the observed numbers of mothers

\begin{tabular}{|c|c|c|c|c|c|c|}
\hline \multirow[t]{2}{*}{ Mother } & \multicolumn{3}{|c|}{ Offspring } & \multirow{2}{*}{$\begin{array}{l}\text { Sum of } \\
\text { mothers }\end{array}$} & \multirow{2}{*}{$\begin{array}{l}\text { Non-breeding } \\
\text { females }\end{array}$} & \multirow[t]{2}{*}{ Males } \\
\hline & $A_{1} A_{1}$ & $A_{1} A_{2}$ & $A_{2} A_{2}$ & & & \\
\hline \multirow[t]{2}{*}{$A_{1} A_{1}$} & 14 & 10 & & 24 & 77 & 26 \\
\hline & 10.3 & 13.7 & & 27.3 & 73.7 & 30.5 \\
\hline \multirow[t]{2}{*}{$A_{1} A_{2}$} & 19 & 29 & 18 & 66 & 178 & 67 \\
\hline & 14.1 & 33 & 18.9 & 65.9 & 178.1 & 68.3 \\
\hline \multirow[t]{2}{*}{$A_{2} A_{2}$} & & 22 & 23 & 45 & 110 & 58 \\
\hline & & 19.3 & 25.7 & 41.9 & 113.2 & 52.2 \\
\hline Sum & 33 & 61 & 41 & 135 & 365 & 151 \\
\hline
\end{tabular}

Table 3. Globicephala melas. Sod-1 locus: observed genotypic distributions, and expected distributions (in italic type) of offspring and males under Hypothesis 3 and of females under Hypothesis 4. The expected numbers of offspring are conditional on the observed numbers of mothers

\begin{tabular}{|c|c|c|c|c|c|c|}
\hline \multirow[t]{2}{*}{ Mother } & \multicolumn{3}{|c|}{ Offspring } & \multirow{2}{*}{$\begin{array}{l}\text { Sum of } \\
\text { mothers }\end{array}$} & \multirow{2}{*}{$\begin{array}{c}\text { Non-breeding } \\
\text { females }\end{array}$} & \multirow[t]{2}{*}{ Males } \\
\hline & $A_{1} A_{1}$ & $A_{1} A_{2}$ & $A_{2} A_{2}$ & & & \\
\hline \multirow[t]{2}{*}{$A_{1} A_{1}$} & 7 & 6 & & 13 & 61 & 33 \\
\hline & 6.7 & 7.3 & & 19.1 & 54.9 & 44.7 \\
\hline \multirow[t]{2}{*}{$A_{1} A_{2}$} & 24 & 32 & 9 & 65 & 173 & 63 \\
\hline & 16.7 & 32.5 & 15.8 & 61.4 & 176.6 & 62.6 \\
\hline \multirow[t]{2}{*}{$A_{2} A_{2}$} & & 35 & 9 & 44 & 117 & 52 \\
\hline & & 22.6 & 21.4 & 41.5 & 119.5 & 40.8 \\
\hline Sum & 31 & 73 & 18 & 122 & 351 & 148 \\
\hline
\end{tabular}

Hypothesis 1, Female gametic selection. In the absence of gametic selection, heterozygous females segregate the alleles $A_{1}$ and $A_{2}$ at a ratio of $1: 1$. Therefore, half of their offspring are expected to be heterozygotes, irrespective of the allele frequency of the male gametes, which is indicated in the expected distributions in Table 1 to 3 . The hypothesis is tested with a single degree of freedom. None of the tests show significant differences (see Table 4). Thus, we conclude that heterozygous females segregate in the expected way.

Hypothesis 2, Random mating. If males mate with females irrespective of the female genotype, we expect that the transmitted male gametes have the same frequencies for all 3 female genotypes. Instead of the 3 allele frequencies necessary to describe the transmitted male gametes in the different female genotypes, a single allele frequency is sufficient, and the hypothesis can be tested with 2 degrees of freedom. Because there were no $A_{2} A_{2}$ homozygotes at the Est-1 locus, random mating could only be tested among the $A_{1} A_{1}$ and $A_{1} A_{2}$ genotypes. In this case, the test has only 1 degree of freedom. For all 3 loci this hypothesis is accepted (Table 4), so we conclude that there is evidence of random mating with respect to the variation at these loci.

for the Est-1 locus was smaller because, as mentioned earlier, no liver samples existed from 6 schools. Below, we present the different hypotheses of the selection component analysis.
Hypothesis 3, Male reproductive selection. In Hypothesis 1 it was shown that females segregate at a ratio of $1: 1$ at all 3 loci. If males also do this, and if the collected males are the fathers of the collected off-

Table 4. Globicephala melas. Tests of the hypotheses in the selection component analysis

\begin{tabular}{|c|c|c|c|c|c|c|c|}
\hline \multirow{2}{*}{ Hypothesis } & \multirow[t]{2}{*}{ df } & \multicolumn{2}{|c|}{ Est-1 } & \multicolumn{2}{|c|}{ Mpi } & \multicolumn{2}{|c|}{ Sod-1 } \\
\hline & & $\chi^{2}$ & $p$ & $\chi^{2}$ & $\mathrm{p}$ & $\chi^{2}$ & $\mathrm{p}$ \\
\hline (1) Mendelian segregation & 1 & 0.05 & 0.82 & 0.97 & 0.32 & 0.02 & 0.90 \\
\hline (2) Random mating & $2^{\circ}$ & 1.39 & 0.24 & 0.57 & 0.75 & 3.18 & 0.20 \\
\hline (3) Male reproductive selection & 1 & 1.74 & 0.19 & 4.87 & 0.03 & 24.43 & 0.00 \\
\hline (4) Female sexual selection & 2 & 5.79 & 0.06 & 0.87 & 0.65 & 3.32 & 0.19 \\
\hline (5) Sex-specific zygotic selection & 2 & 5.80 & 0.06 & & & & \\
\hline (6) Zygotic selection & 1 & 0.05 & 0.82 & & & & \\
\hline Sum & 8 & 14.82 & 0.06 & & & & \\
\hline
\end{tabular}


spring, the allele frequencies of transmitted male gametes should reflect the genotypic distribution of males. At the Est-1 locus this hypothesis is accepted, but it is rejected at the $5 \%$ level at the other 2 loci (Table 4). A look at Tables $2 \& 3$ reveals the reason. At the Mpi locus, the frequency of transmitted $A_{1}$ alleles is 0.519 , whereas the frequency of this allele among the sampled males is 0.394 . The expected distribution of males under Hypothesis 3 in Table 2 yields the following frequencies of the 3 genotypes: $A_{1} A_{1}$ 0.202, $A_{1} A_{2}$ 0.452 , and $A_{2} A_{2} 0.346$, where $A_{1}$ has a frequency of 0.428 . The frequency of the transmitted $A_{1}$ alleles is too high to be accounted for by the observed distribution of males. At the Sod-1 locus, the difference in allele frequencies of the transmitted male gametes and of the observed males is even higher. The offspring have received $A_{1}$ male gametes at a frequency of 0.733 , whereas the males carry this allele at a frequency of 0.436 . The expected distribution under Hypothesis 3 is: $A_{1} A_{1}$ 0.302, $A_{1} A_{2} 0.423$, and $A_{2} A_{2}$ 0.276, where allele $A_{1}$ has a frequency of 0.514 . As at the $M p i$ locus, the expected distribution under Hypothesis 3 cannot account for both the distribution of the observed males and the frequencies of the transmitted alleles. The fathers of the sampled offspring must have transmitted allele $A_{1}$ at a higher frequency.

Hypothesis 4, Female sexual selection. If females mate irrespective of their own genotype at the studied loci, we expect the genotypic distributions of pregnant and non-pregnant females to be the same. This hypothesis is not dependent on any of the previous hypotheses and can be tested with a standard test for homogeneity between the 2 classes. This test has 2 degrees of freedom. The genotypic distributions of these 2 female classes do not differ at any of the 3 loci, so the selection component analysis does not detect an effect of any of the alleles on reproductive success. This indicates that the chance that a female will become a mother is independent of the genotype she carries at the studied loci.

Hypothesis 5, Differential zygotic selection between the sexes. If natural selection acts on the studied polymorphisms in the form of zygotic (or viability) selection, one may ask whether it has the same effect in both sexes. This is done in the selection component analysis by estimating a common genotypic distribution for the 2 female classes and the males, under the assumption that this group carries alleles with the same frequencies as transmitted to the offspring. This hypothesis is dependent on the previous hypotheses and therefore cannot be applied to the polymorphisms at the Mpi and the Sod-1 loci. The test for this hypothesis is not significant for the Est-1 locus, so we conclude that there is no detectable zygotic selection at this locus. If natural selection is operative, it has the same impact on the 2 sexes.
At the other 2 loci we can make a hypothesis about zygotic selection by comparing the genotypic distribution of all the females - which is homogeneous within this sex, as shown in Hypothesis 3 - with the genotypic distribution of the males. This hypothesis does not depend on any of the previous hypotheses, since it does not include the distributions of the offspring. It can be tested with a standard test for homogeneity, which has 2 degrees of freedom. The test statistics and the probabilities of observing more extreme values at the $M p i$ and the Sod -1 loci are $\chi^{2}=2.90, p=0.23$ and $\chi^{2}=4.21$, $p=0.12$, respectively. So, there is no indication in the present sample that natural selection acts on the variation at these 2 loci via a different zygotic survival among the sexes.

Hypothesis 6, Zygotic selection. If natural selection acts through differential zygotic survival of the different genotypes, and it is assumed that (1) there is no fecundity selection and (2) polymorphism is at equilibrium with respect to selection, genotypic distributions would deviate from the expected Hardy-Weinberg distribution, where allele frequencies are estimated from the total adult group and alleles transmitted to the offspring group. This hypothesis is dependent on the previous hypotheses and is only open to reasonable interpretation if the previous hypotheses have been accepted. Therefore, this hypothesis was not tested for the Mpi and Sod-1 loci.

Hypothesis 6 is accepted for the Est- 1 locus. Thus, we accept that there is no evidence that natural selection acts on this polymorphism and that there is random mating with respect to the variation at this locus. The polymorphism can therefore be described with a single parameter: the frequency of $A_{1}$ is 0.726 .

We can apply a weaker test for zygotic selection at the Mpi and Sod-1 loci. Under Hypothesis 5, we accepted a homogeneous genotypic distribution of the observed adult classes. We can now ask whether these distributions are in accordance with the expected Hardy-Weinberg distributions, where allele frequencies have been estimated from the observed genotypes of the adults. This is a standard test for Hardy-Weinberg proportions and is given in Table 5. There is no

Table 5. Clobicephala melas. Observed and expected (in italic type) Hardy-Weinberg distributions of the sum of all 3 adult groups at the Mpi and the Sod-1 loci

\begin{tabular}{llllccc|}
\hline Locus & $A_{1} A_{1}$ & $A_{1} A_{2}$ & $A_{2} A_{2}$ & $\mathrm{n}$ & $\chi^{2}$ & $\mathrm{p}$ \\
\hline Mpi & 127 & 311 & 213 & 651 & 0.49 & 0.48 \\
& 122.6 & 319.8 & 208.6 & & & \\
Sod-1 & 107 & 301 & 213 & 621 & 0.00 & 1.00 \\
& 106.8 & 301.5 & 212.8 & & & \\
\hline
\end{tabular}


evidence of any deviation from the expected distributions at the Mpi and Sod-1 loci. It seems unlikely that zygotic selection acts on these 2 polymorphisms.

\section{DISCUSSION}

At the Est-1 locus all hypotheses of the selection component analysis were accepted, indicating that there was no evidence that natural selection acted on this polymorphism. At the other 2 loci, Mpi and Sod-1, Hypothesis 3 (no male reproductive selection) was rejected in both cases. Apart from this rejection, there was no evidence that other components of natural selection affected these 2 polymorphisms.

We interpret the rejection of no male reproductive selection as being a result of the migration of males between the schools, based on either of the following 2 possible explanations: (1) segregation in heterozygous males is not Mendelian, or (2) the genotypic distribution of males that have fathered offspring differs from the observed genotypic distribution of the males that have been collected. Thus, the rejection of Hypothesis 3 could be caused either by gametic or by sexual selection in males, or by many other factors which might also skew male reproductive success. Such an example of a relation between fitness components and specific genotypes has been found in female red deer (Pemberton et al. 1991).

The selection component analysis assumes that a single population has been sampled. The rejection of Hypothesis 3 can, in this case, be produced by either of the causes mentioned above. We pooled several schools of the long-finned pilot whale, chosen to represent the largest homogeneous sample of this species. This procedure probably reduces the noise arising from the significant genetic differences found between the different schools. This genetic differentiation could cause a rejection of a hypothesis in the selection component analysis. The pooling procedure allows for an additional explanation of the observed male reproductive selection. If males have a tendency to migrate between different schools of whales, the male group included in the present sample might have come from schools with different allele frequencies. This could explain why the genotypic distribution of males differs from that of fathers that transmitted gametes to the offspring. At the Est-1 locus the difference in allele frequencies between males and transmitted male gametes is 0.11 , which is of the same order as at the Mpi locus (0.13). Despite this, Hypothesis 3 was accepted, which might be a Type II error because of the lower sample size for the Est-1 locus. The observed phenomenon might therefore be quite general for different loci. The allele frequencies of mature males in the ex- cluded schools were 0.500 at the Mpi locus, 0.417 at the Sod-1 locus and 0.724 at the Est-1 locus, which for the Est-1 and the Mpi loci is sufficient to explain the difference between the observed and transmitted gametes (Est-1, 0.750; Mpi, 0.519) in the present sample. For the Sod-1 locus the difference is too large (transmitted, 0.733; observed, 0.436) to be accounted for by the allele frequency of excluded males (0.417), which could be explained by selection or by the possibility that gametes could come from other, nonobserved schools and still be in the meta-population.

The way we selected the data has a 'homogenizing' effect that acts in the opposite direction of our explanation for rejection of Hypothesis 3 . We believe, therefore, that the discovered rejection is caused by a real phenomenon and that male migration or gene flow between the schools is a reasonable explanation. The greatest discrepancy in allele frequency difference between males and offspring was found at the Sod-1 locus. In this case, the difference between allele frequencies of fathers and those of mothers must also have been relatively large. With an allele frequency of $p_{o}$ in females and $p_{\sigma}$ in males, the offspring are expected to show a heterozygote excess of $\left(p_{o}-p_{\circ}\right)^{2} / 2$ relative to the Hardy-Weinberg proportions based on the average gene frequencies of the 2 sexes. Table 3 shows that the genotypic distribution of the offspring contains an excess of heterozygotes that is significantly different from the Hardy-Weinberg distribution $\left(\chi^{2}=\right.$ 5.47, $\mathrm{df}=1, \mathrm{p}=0.02 \mathrm{j}$. This deviation is probably due to the above-mentioned factor.

Our results are in accordance with the findings of Amos et al. (1991), who studied 5 Faroese long-finned pilot whale schools consisting of 34 mother-offspring combinations. They showed that for $88 \%$ of the foetuses, the fathers were not among the accompanying mature males. Analysis of the paternal alleles also indicated that the males are polygynous and that the male contribution changes from year to year. In addition, previously known facts about the social structure of Globicephala melas indicate that the schools are composed of an excess of mature females relative to males (Sergeant 1962, Martin et al. 1987). One explanation for the difference in numbers of females and males could be that males have a total higher mortality rate than females, as shown for the short-finned pilot whale Globicephala macrorhynchus by Kasuya \& Marsh (1984). Males of this species are also polygynous. The social structure of the short-finned pilot whale school is formed by a breeding unit composed of aduit males and females of different reproductive stages, and by immature and pubertal individuals. Adult males may migrate between the schools and form schools dominated by adult males. Female associations probably persist for a longer period and females 
and juveniles in the schools are presumably related (Kasuya \& Marsh 1984). This social structure resembles the social structure of the long-finned pilot whale. Another odontocete with a related social structure is the sperm whale Physeter macrocephalus (Whitehead 1987). Here the basic social entity consists of adult females with offspring and immature males. In sperm whales, old mature males observed off the Galápagos Islands exhibited a searching strategy, moving from one school to the next during the mating season (Whitehead 1987). At other times of the year they occurred in small groups or as solitary individuals, while the young mature males occurred in bachelor groups (Gaskin 1985). Yet no bachelor groups have been observed for the long-finned pilot whale, which indicates that the males should be found within the schools. Amos et al. (1991) also suggest that the school structure is basically matrilineal and that males do not mate within their school. This supports our interpretation of the rejection of Hypothesis 3 .

One explanation for the genetic differences found between schools of the long-finned pilot whale in the North Atlantic could be that the population structure comprises an assemblage of schools, each consisting of a number of female family groups. The schools are genetically connected through migration of males and, occasionally, through fusions and fissions of a number of schools. The males that enter a school may be genetically differentiated from the females in the school, which increases heterozygosity among the offspring. The difference in allele frequencies between males and females could be increased by a low effective number of males that mate. Counteracting the increased heterozygosity in the offspring is the fact that the schools are relatively small and that genetic drift produces different allele frequencies in the schools which, due to the Wahlund effect, results in an excess of homozygotes for the tatal assemblage of schools. The combination of these forces causes an overall agreement of the genotypic distributions with HardyWeinberg proportions at the 3 studied loci.

Recent observations of mitochondrial genetic differences between sympatric populations or subpopulations and several distinct seasonal subpopulations suggest that different behavioral strategies (different foraging strategy and different maternal migratory destinations) may explain other findings similar to those in the present study (Baker et al. 1990, Bigg et al. 1990, Hoelzel \& Dover 1991).

The selection component analysis of Christiansen \& Frydenberg (1973) was developed for an organism with non-overlapping generations. Some of the individuals that have been grouped into a specific category in this study could in previous years have belonged to other groups. It is known from an analysis of ovaries in the 19 schools (G. Desportes pers. comm.) that the group of non-pregnant females included some that had bred in previous years. Some of the females that had not yet bred would probably have bred in later years, had they not been caught. A possible means of including such phenomena in the analysis would be to use an extension of the selection component method for populations with overlapping generations described by Christiansen \& Frydenberg (1976); this aproach was applied by Christiansen et al. (1977) in a population of the live-bearing marine teleost Zoarces viviparous. However, due to the relatively small sample of long-finned pilot whales, the use of this extension of selection component analysis would probably be of limited value.

Acknowledgements. This study was made possible by the great help of the staff at the Faroese Natural History Museum, Faroe Islands, and the Faroese Director of Fisheries, Kjartan Hoydal, Faroe Islands. Special thanks to Kate Sanderson for proof-reading the English. This study was funded by the Danish Natural Research Council, Grant no. 11-7274.

\section{LITERATURE CITED}

Amos, W., Barrett, J., Dover, G. (1991). Breeding behaviour of pilot whales revealed by DNA fingerprinting. Heredity 67 $49-55$

Andersen, L. W. (1988). Electrophoretic differentiation among local populations of the long-finned pilot whale, Globicephala melaena, at the Faroes Islands. Can. J. Zool 66: $1884-1892$

Andersen, L. W. (1993). Further studies on the populations structure of the long-finned pilot whale, Globicephala melas, off the Faroe Islands. Int. Whal. Commn Spec. Rep Ser., Spec. Issue 14: in press

Baker, C. S., Palumbi, S. R., Lambertsen, R. H., Weinrich M. T., Calambokidis, J., O'Brien, S J. (1990). Influence of seasonal migration on geographic distribution of mitochondrial DNA haplotypes in humpback whales. Nature $344: 238-240$

Bigg, M. A., Olesiuk, P. F., Ellis, G. M., Ford, J. K., Balcomb, K. C. (1990). Social organization and genealogy of resident killer whales (Orcinus orca) in the coastal waters of British Columbia and Washington State. Int. Whal. Commn Spec. Rep. Ser., Spec. Issue 12: 383-406

Bloch, D. (1989-1990). Studies on the long-finned pilot whale in the Faroe Islands, 1976-86. Fródskaparrit 38/39: 35-61

Brown, S. G. (1961). Observations of pilot whales (Globicephala) in the North Atlantic. Norsk Hvalfangst-Tid. 50: $225-254$

Buckland, S. T., Cattanach, K. L., Gunnlaugsson, T. H., Bloch, D., Lens, S., Sigurjonsson, J. (1993). Abundance and distribution of long-finned pilot whales in the North Atlantic, estimated from NASS-87 and NASS-89 data. Int. Whal. Commn Spec. Rep. Ser., Spec. Issue 14: in press

Christiansen, F. B., Frydenberg, O. (1973). Selection component analysis of natural polymorphisms using population samples including mother-offspring combinations. Theor. Popul. Biol. 4: 425-445

Christiansen, F. B., Frydenberg, O. (1976). Selection component analysis of natural polymorphisms using mother-off- 
spring samples of successive cohorts. In: Karlin, S., Nevo, E. (eds.) Population genetics and ecology. Academic Press, New York, p. 277-304

Christiansen, F. B., Frydenberg, O., Simonsen, V (1973). Genetics of Zoarces populations. IV. Selection component analysis of an esterase polymorphism using population samples including mother-offspring combinations. Hereditas 73: 291-304

Christiansen, F. B., Frydenberg, O., Simonsen, V. (1977). Genetics of Zoarces populations. X. Selection component analysis of the EstIII polymorphism using samples of successive cohorts. Hereditas 87-129-150

Desportes, G. (1985). La nutrition des Odontocetes en Atlantique Nord-Est. Ph.D. thesis, Universite de Poitiers, Poitiers

Gaskin, D. E. (1985). The ecology of whales and dolphins. Heinemann Educational Books, Inc., London

Hoelzel, A. R., Dover, G. A. (1991). Genetic differentiation between sympatric killer whale populations. Heredity 66: $191-195$

Kasuya, T., Marsh, H. (1984). Life history and reproductive biology of the short-finned pilot whale, Globicephala macrorhynchus, off the Pacific coast of Japan. Rep. int. Whal. Commn, Spec. Issue 6: 259-310

Martin, A. R., Reynolds, P., and Richardson, M. E. (1987). As-

This article was submitted to the editor pects of the biology of the pilot whale (Globicephala melaena) in recent mast strandings on the British coast. J. Zool. 211. 11-23

Østergaard, H., Christiansen, F. B. (1981). Selection component analysis of natural polymorphisms using population samples including mother-offspring combinations, II. Theor. Popul. Biol. 19: 378-419

Pemberton, J., Albon, S. D., Guinness, F. E., Clutton-brock, $T$ H. (1991). Countervailing selection in different fitness components in female red deer. Evolution 45: 93-103

Sergeant, D. E. (1962). The biology of the pilot whale Globicephala melaena (Traill) in Newfoundland waters. Bull. Fish. Res. Bd Can. 132: 1-84

Siegismund, H. R., Christiansen, F. B. (1985). Selection component analysis of natural polymorphisms using population samples including mother-offspring combinations, III. Theor. Popul. Biol. 27' 268-297

Sokal, R. R., Rohlf, F. J. (1981). Biometry. W. H. Freeman and Company, New York

Whitehead, H. (1987). Social organization of sperm whales off the Galápagos: implications for management and conservation. Rep. int. Whal. Commn 37: 195-199

Williams, C. J., Anderson, W. W., Arnold, J. (1990). Generalized linear modeling methods for selection component experiments. Theor. Popul. Biol. 37: 389-423

Manuscript first received: August 27, 1993

Revised version accepted: November 15, 1993 